\title{
Medulloblastoma of the Cerebellopontine Angle in a Child: A Rare Entity
}

\author{
Madan Kumar Solanki ${ }^{*}$, Dilip Ramrakhiani² \\ ${ }^{1 *} \mathrm{MD}$ Resident, 2 Professor, \\ Department of Pathology, S.M.S. Medical College, Jaipur, Rajasthan, India.
}

\begin{abstract}
Cerebellopontine (CP) angle Medulloblastoma is a quite uncommon presentation in clinical practice, especially in children. We report such a case in a 12 years old female patient with clinical history of headache, altered sensorium, vertigo, gait ataxia, left side facial paresis and hearing loss. Preoperative axial MR imaging showed an ill-defined heterogenous lesion in left $\mathrm{CP}$ angle region with involvement of left middle cerebellar peduncle, left cerebellar hemisphere and cerebellar vermis. Post contrast scan showed heterogenous enhancement. Intra operative frozen cytology was suggestive of malignant round cell neoplasm. The subsequent histopathology and immunohistochemistry favoured the diagnosis of Medulloblastoma.
\end{abstract}

\section{INTRODUCTION}

Medulloblastoma (MB) is a highly malignant neuroepithelial tumor of the posterior fossa classified WHO grade IV. Medulloblastoma is mainly a brain tumor of pediatric age that account for $10 \%$ of all intracranial neoplasms and $29 \%$ of all posterior fossa tumors in children whereas they accounts for less than $1 \%$ of CNS adult neoplasms. ${ }^{1-3}$ In children most medulloblastomas (MBs) are encountered in the vermis whereas in adults the cerebellar hemispheres is usual site. ${ }^{1-3}$

Typical and atypical MRI features have been reported in MBs: mostly present with well-defined margins, isointense signal on $\mathrm{T} 1$, hyperintense signal on T2-images, and marked enhancement on T1- postcontrast scan. In rare cases they present with ill-defined margins, hypointensity signal on $\mathrm{T} 2$, mild or nodular enhancement. ${ }^{4-6}$

Cerebellopontine angle (CPA) is an uncommon site and only 39 cases have been reported to date in best of our knowledge. We report a further case of CPA MB in a 12 year old female child.

\section{CASE REPORT}

A 12 year old female who presented with a headache, altered sensorium, vertigo, gait ataxia, left side facial paresis and hearing loss around 8 months before admission. BERA examination was indicative of retrocochlear pathology. Non contrast CT scan showed hyperdense mass lesion in left cerebellopontine angle with supratentorial extension causing effacement of 4 'th ventricle, compression over brain stem with peri-lesional oedema. MRI brain with GD showed presence of large ill-defined heterogenous
Key Words: Medulloblastoma, Cerebellopontine (CP) angle tumor, Child, MRI.

\section{${ }^{*}$ Correspondence to:}

\section{Dr. Madan Kumar Solanki}

MD Resident,

Department of Pathology,

S.M.S. Medical College, Jaipur, Rajasthan, India.

Article History:

Received: 27-09-2016, Revised: 21-10-2016, Accepted: 27-10-2016

\begin{tabular}{|l|c|}
\hline \multicolumn{2}{|c|}{ Access this article online } \\
\hline Website: & Quick Response code \\
www.jjmrp.com & \\
\hline DOI: & \\
10.21276/jmrp.2016.2.6.025 & \\
\hline
\end{tabular}

intensity lesion of size $53 \times 53 \times 58 \mathrm{~mm}$ noted in the left CP angle region extending in the pons with involvement of left middle cerebellar peduncle. It was causing effacement of 4 'th ventricle and was involving left cerebellar hemisphere and cerebellar vermis. The tumor was showing heterogenous enhancement on post GD contrast scan. The patient underwent a left suboccipital craniotomy with tumor decompression. On exposure of the left CPA, a whitish grey white mass, soft in consistency was found. The tumor was partially suckable and vascular. The intra operative frozen cytology showed fragments of hyperchromatic cells with round nuclei, high N/C ratio at places arranged in rosette pattern and was suggestive of malignant round cell neoplasm.

We subsequently received several grey white soft tissue pieces measuring $5 \times 5 \mathrm{~cm}$ for histopathological examination in our department. The histopathological examination was suggestive of medulloblastoma (WHO Grade IV). The subsequent immunohistochemistry showed synaptophysin positivity and was negative for GFAP. MIB score was $20 \%$, which favoured the final diagnosis of medulloblastoma. The patient died two days after the surgery.

\section{DISCUSSION}

The most common cause of childhood oncological death is brain tumors of which medulloblastoma is the most common malignant pediatric brain tumor. ${ }^{7} \mathrm{MB}$ is an embryonic neoplasm of central nervous system arising from undifferentiated neuroepithelial cells (primitive neuroectodermal tumor, PNET). ${ }^{8}$ MBs are the most 
common posterior fossa pediatric tumor, with approximately $50 \%$ of then encountered in the first decade of life. The tumor usually originate from the vermis and extends into the fourth ventricle. ${ }^{1,2}$

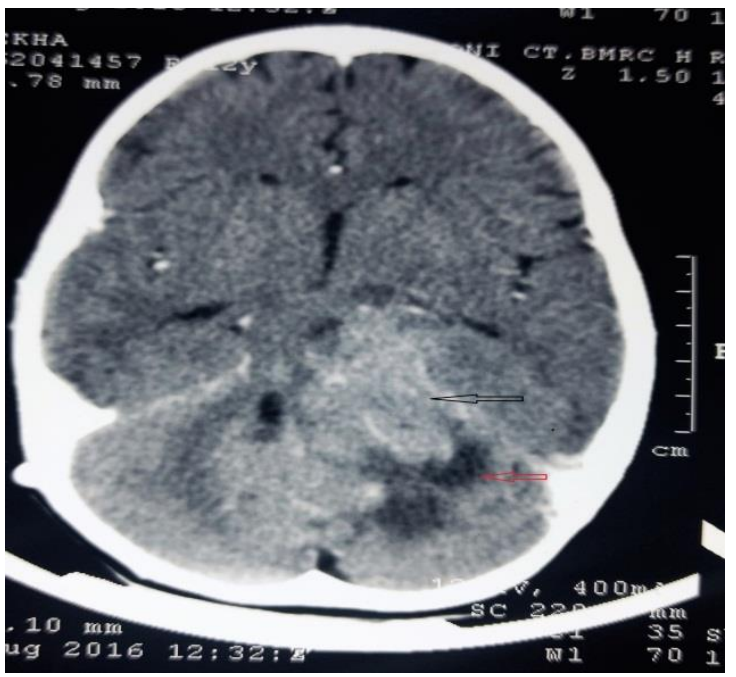

Fig 1: Axial Non contrast CT scan showing hyperdense mass lesion in left cerebellopontine angle (black arrow) causing effacement of 4 'th ventricle with peri-lesional edema.(Red arrow)

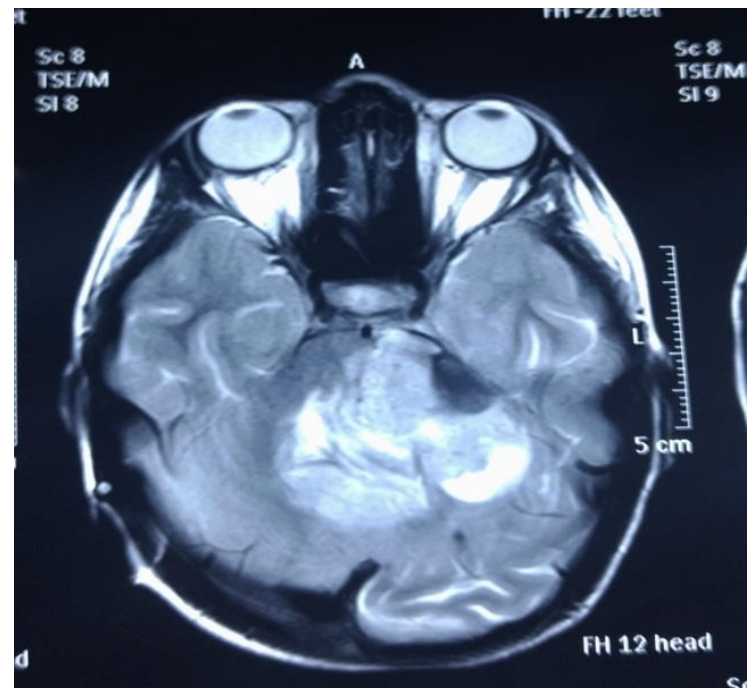

Fig 3: T2 weighted MRI shows illdefined heterogenous intensity lesion in left $C P$ angle extending in the pons with involvement of left cerebellar peduncle.

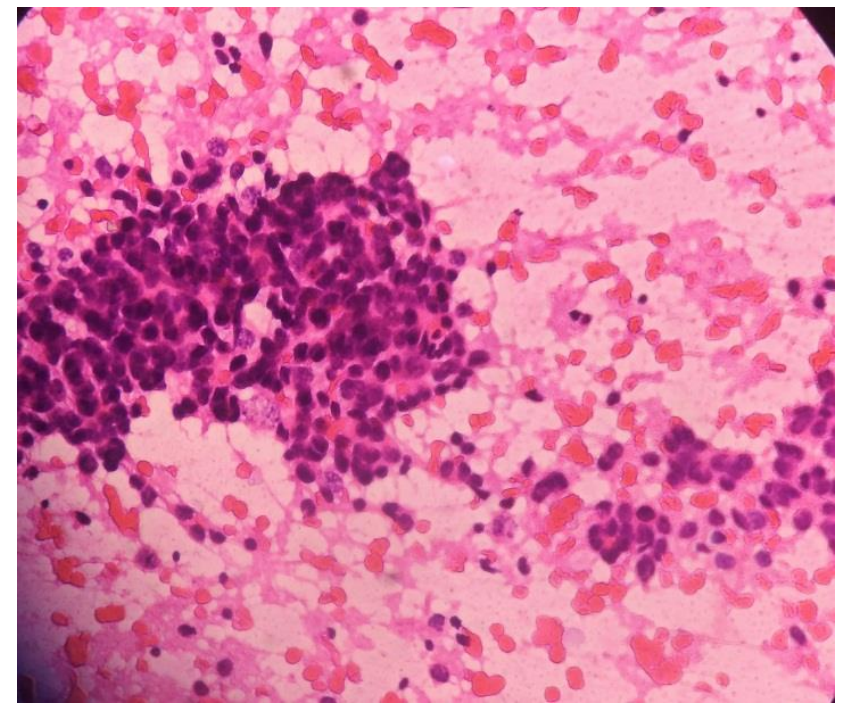

Fig 5: Intra operative frozen cytology showing round hyperchromatic cells with high $\mathrm{N}: \mathrm{C}$ ratio.
Very rarely MBs develop in the CPA and only 39 cases have been reported in the literature to date. Mean size at time of presentation is of $30 \mathrm{~mm}$.

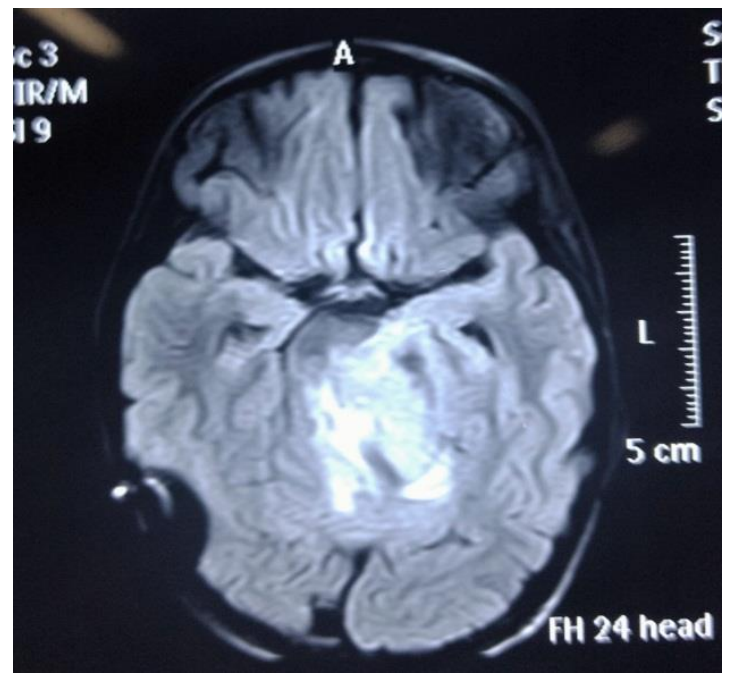

Fig 2: Axial T1 weighted MRI shows illdefined heterogenous intensity lesion in left CP angle extending in the pons

with involvement of left cerebellar peduncle.

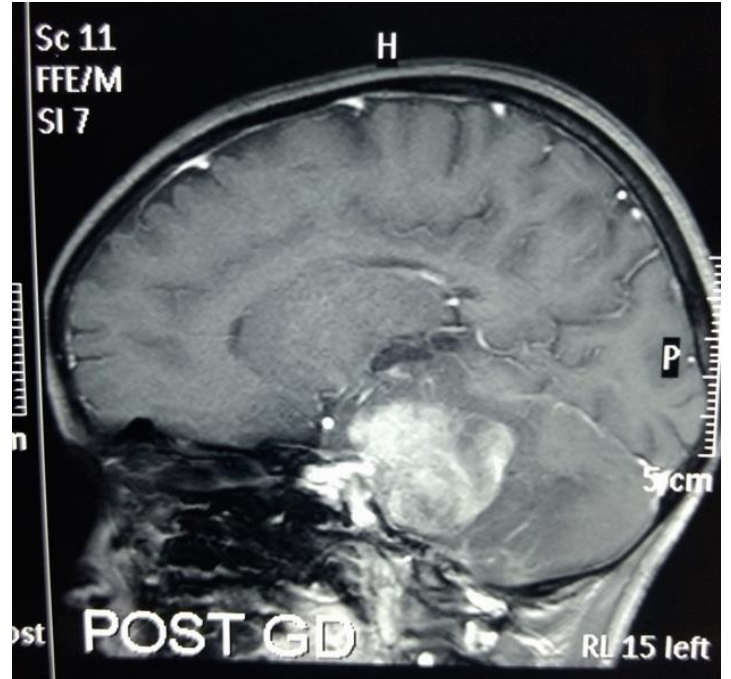

Fig 4: Sagittal view of post GD contrast scans showing heterogenous enhancement.

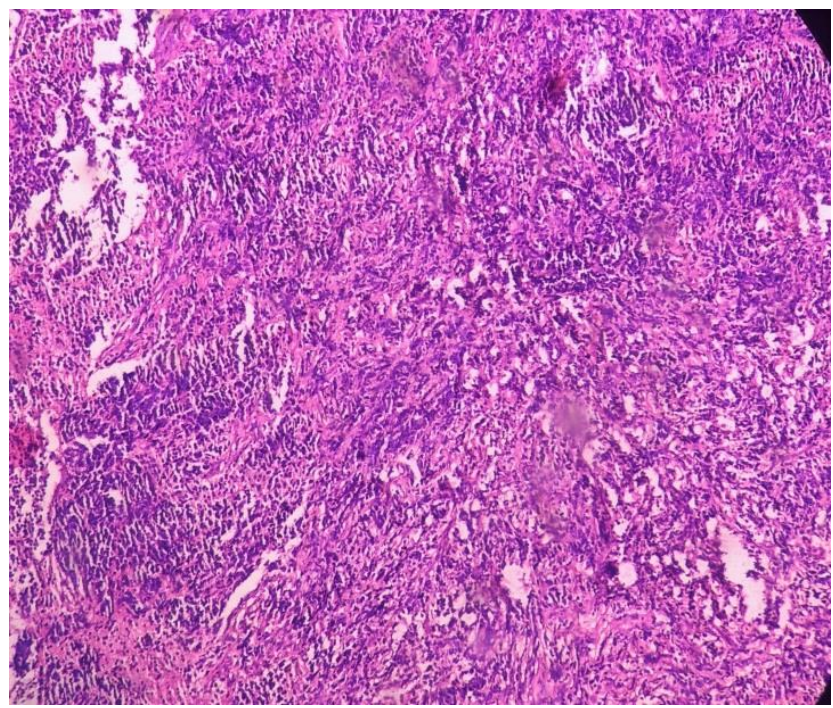

Fig 6: Low power (10X) view of H\&E stain showing round hyperchromatic malignant cells infiltrating into the brain parenchyma. 


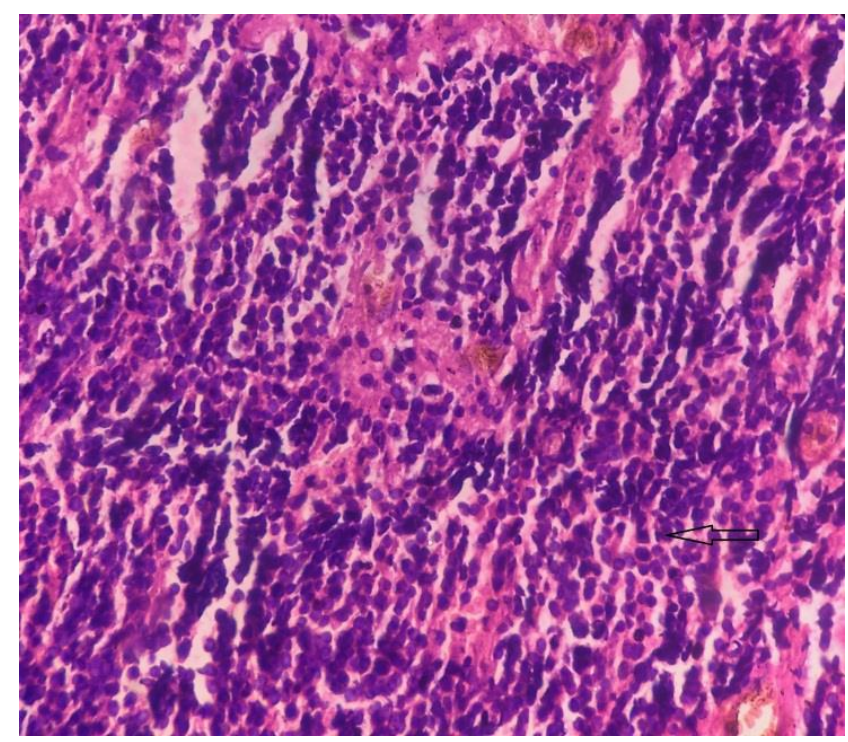

Fig 7: High power (40X) view showing round hyperchromatic cells with high $\mathrm{N}: \mathrm{C}$ ration at places arranged in rosette pattern(arrow).

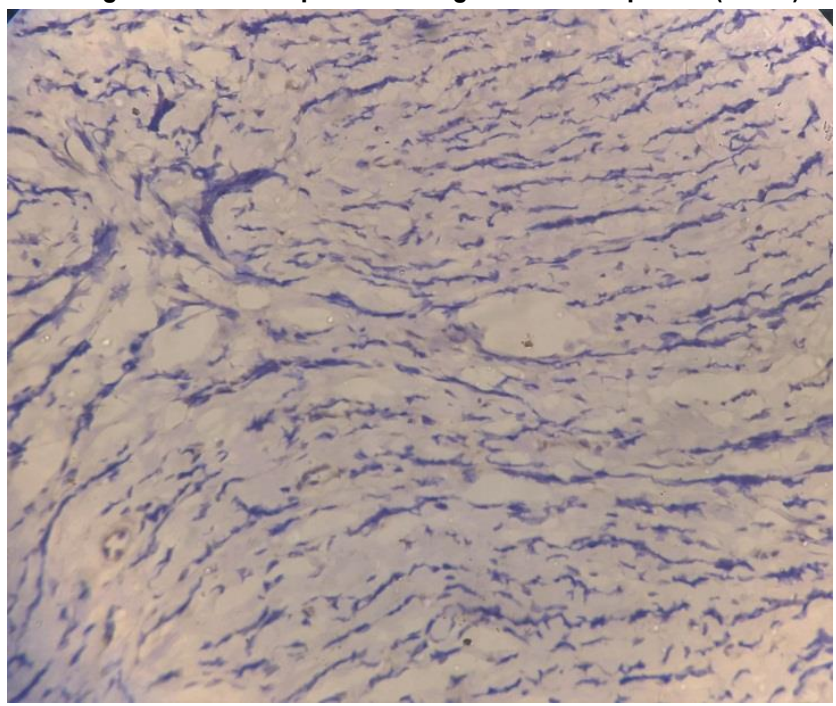

Fig 9: Tumor show negative immunostaining for GFAP.

The symptoms usually shorter in duration than other posterior fossa tumors. Some clinical features that may help distinguish them from other CPA lesions: Vth, VI'th, VII' th, VIII' th and lower cranial nerve involvement, and signs of cerebellar dysfunction are commonly note in CPA lesions. Hearing impairment and VII th nerve involvement is usually less common and a late feature of CPA MB.

Only 5 of the 38 CPA MBs published so far presented with hearing impairment as initial symptom. Classic and desmoplastic MBs are the most common histological variants. There are no pathognomonic MRI criteria for differentiating them, and the only characteristic found is an iso- or hypointensity on T2/FLAIR sequence. ${ }^{8-15} \mathrm{MB}$ has variable appearances on MRI in both children and adults. ${ }^{4}$

In most reported cases, CPA MBs have a homogeneous hypointensity on T1-, a heterogeneous hyperintensity on T2/FLAIR and enhance heterogeneously and strongly after contrast. In most cases classic MB had a high signal on T2 and a low signal on T1. In half cases of desmoplastic MB the lesion had an isointense signal on T2. In all variants the enhancement was in most cases intense and homogeneous. ${ }^{6,9}$ Very infrequently, MBs involving the CPA may present with widening and deep invasion

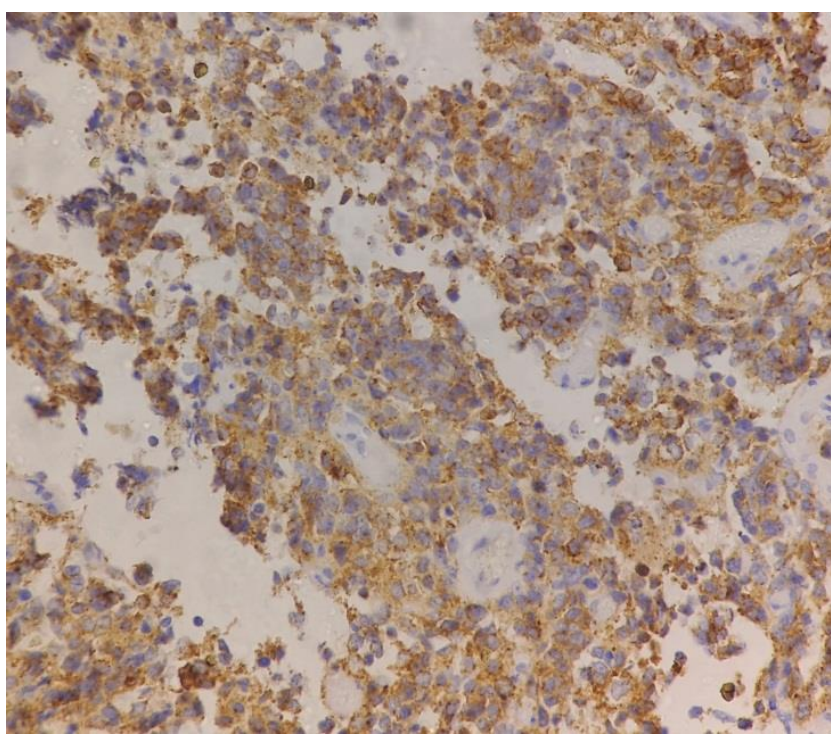

Fig 8: Malignant cell showing synaptophysin positivity

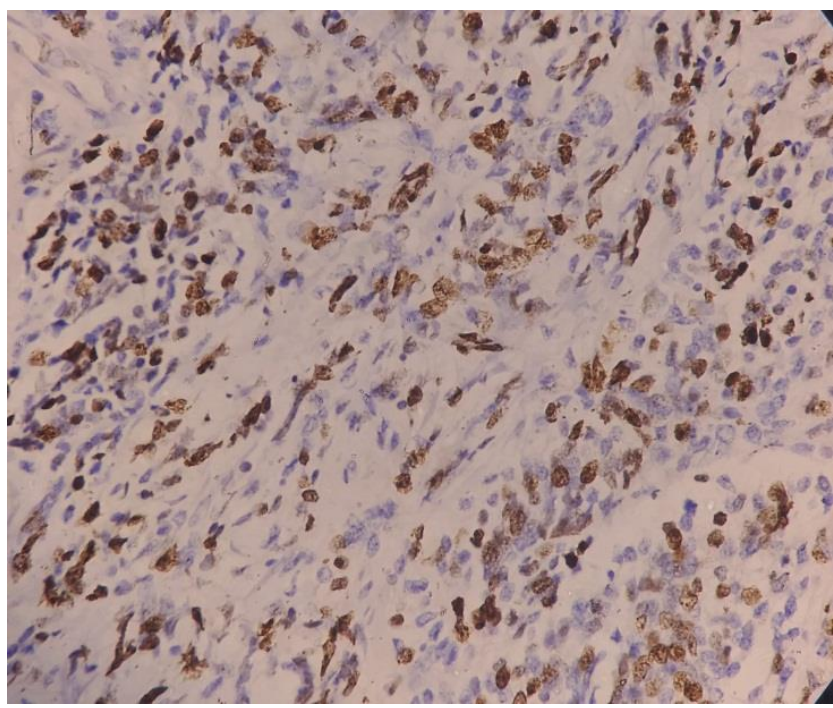

Fig 10: MIB-LI score $20 \%$ high power view.

of the IAC, simulating an acoustic neuroma, or with a dural-based appearance, without bony involvement or hyperostosis, simulating a petrosal meningioma. ${ }^{12,13,17}$

In our reported case the tumor had heterogenous hyperintensity on T2 Wl and heterogenous enhancement on post contrast scan. Intra-axial tumors that may have an exophytic mass projecting into the CPA are astrocytoma and ependymoma. Occasionally, brain stem glioma, metastasis and lymphoma result in similar findings, but metastases are not likely children tumors. ${ }^{11}$

\section{CONCLUSION}

Cerebellopontine angle is a very rare location of medulloblastoma, especially in children and mostly presents intra-axially. However, it is important to keep in mind the rare possibility of medulloblastoma presenting extra-axially. Its occurrence in the CP angle can confuse the nature of the lesion. Long term survival in these patients is very poor.

\section{REFERENCES}

1. Roberts RO, Lynch CF, Jones MP, Hart MN (1991) Medulloblastoma: a population-based study of 532 cases. J Neuropathol Exp Neurol 50: 134-144. 
2. Maleci A, Cervoni L, Delfini R (1992) Medulloblastoma in children and in adults: a comparative study. Acta Neurochir (Wien) 119: 62-67.

3. Choux M, Lena G, Gentet JC, Paredes AP (2001) Medulloblastoma, Pediatric Neurosurgery, Surgery of the developing nervous system, (4thedn). Philadelphia, Saunders, USA.

4. Levy RA, Blaivas M, Muraszko K, Robertson PL (1997) Desmoplastic medulloblastoma: MR findings. AJNR, Am J Neuroradiol 18: 1364-1366.

5. Malheiros SMF, Carrete Jr H, Stávale JN, Santos AJ, Gabbai $\mathrm{AA}$, et al. (2003) MRI of medulloblastoma in adults. Neuroradiology 4: 463-467.

6. Fruehwald-Pallamar J, Puchner SB, Rossi A, Garre ML, Cama $A$, et al. (2011) Magnetic resonance imaging spectrum of medulloblastoma. Neuroradiology 53: 387-396.

7. Paul A. Northcott, David J. H. Shih1, John Peacock (2012) Subgroup-specific structural variation across 1,000 medulloblastoma genomes, Nature , 2 August 2012; 488; 49-56.

8. Louis DN, Ohgaki H, Wiestler OD, Cavenee WK, Burger PC, et al. (2007) The 2007 WHO classification of tumours of the central nervous system. Acta Neuropathol 114: 97-109.

9. Yamada S, Aiba Y, Hara M (1993) Cerebello-pontine angle medulloblastoma: case report and literature review. $\mathrm{Br} J$ Neurosurg 7: 91-94.

10. Spina A, Boari N, Gagliardi F, Franzin A, Terreni MR, et al. (2013) Review of cerebellopontine angle medulloblastoma. $\mathrm{Br} J$ Neurosurg 27: 316-320.

11. Ahn MS, Jackler RK (1997) Exophytic brain tumours mimicking primary lesions of the cpa. Laryngoscope 107: 466-471.

12. Kumar R, Achari G, Banerjee D, Chhabra D (2001) Uncommon presentation of medulloblastoma. Child's Nerv Sys 17: $538-542$.
13. Akay KM, Erdogan E, Izci Y, Kaya A, Timurkaynak E (2003) Medulloblastoma of the cerebellopontine angle. Neurol Med Chir (Tokyo): 43: 555-558.

14. Gil-Salu JL, Rodriguez-Pena F, Lopez-Escobar M, Palomo MJ (2004) Medulloblastoma de presentacion extra-axial en el angulo pontocerebeloso. Neurocirurgia 15: 285-289

15. Jaiswal AK, Mahapatra AK, Sharma MC (2004) Cerebellopontine angle medulloblastoma. J Cli Neuroscience 11: 42-45.

16. Yoshimura J, Nishiyama K, Fukuda M, Watanabe M, Igarashi $\mathrm{H}$, et al. (2009) Adult cerebellopontine angle medulloblastoma originating in the pons mimicking focal brainstem tumour. $J$ Neuroimaging 19: 385-387.

17. Furtado SV, Venkatesh PK, Dadlani R, Reddy K, Hegde AS (2009) Adult medulloblastoma and the "dural-tail" sign: rare mimic of a posterior petrous meningioma. Clin Neurol Neurosurg 111: 540-543.

Source of Support: Nil. Conflict of Interest: None Declared.

Copyright: () the author(s) and publisher. IJMRP is an official publication of Ibn Sina Academy of Medieval Medicine \& Sciences, registered in 2001 under Indian Trusts Act, 1882.

This is an open access article distributed under the terms of the Creative Commons Attribution Non-commercial License, which permits unrestricted non-commercial use, distribution, and reproduction in any medium, provided the original work is properly cited.

Cite this article as: Madan Kumar Solanki, Dilip Ramrakhiani. Medulloblastoma of the Cerebellopontine Angle in a Child: A Rare Entity. Int J Med Res Prof. 2016; 2(6):124-27.

DOI: 10.21276/ijmrp.2016.2.6.025 